\title{
Estudo sobre o Respeito ao Princípio da Autonomia em Crianças e/ ou Adolescentes sob Tratamento Oncológico Experimental, através do Processo de Obtenção do Consentimento Livre e Esclarecido Study on the Respect for the Principle of Autonomy Concerning Children and/ or Adolescents under Experimental Oncology Treatment through a Term of Informed Consent \\ Estudio sobre el Respeto al Principio de la Autonomía en Niños y/o Adolescentes, bajo Tratamiento Oncológico Experimental, a través del Proceso de Obtención del Consentimiento Libre y Esclarecido
}

Vânia Maria Fernandes Teixeira1', Marlene Braz²

\section{Resumo}

O presente estudo se propôs a analisar o respeito ao princípio da autonomia em crianças e/ou adolescentes, sob tratamento oncológico experimental, através do processo de obtenção do Termo de Consentimento Livre e Esclarecido (TCLE), para fins de pesquisa, por meio de um estudo de casos, de caráter exploratório, de cunho qualitativo. Os dados foram obtidos através de entrevistas temáticas e interpretados pela análise indiciária. Foram entrevistados: três crianças, um adolescente, quatro pesquisadores e quatro mães. Os resultados mostraram que a autonomia, mesmo relativa, da criança e/ou adolescente, não é levada em consideração, o que se traduz pela não obtenção do TCLE, uma vez que os pais e pesquisadores acreditam que essas crianças e/ou adolescentes não são capazes de entender os riscos e benefícios da pesquisa. Neste sentido, a decisão dos pais, em permitir a participação da criança e/ou adolescente nesse tratamento experimental, foi baseada na esperança de cura para o filho e, por isso, são eles quem assinam o TCLE. Tanto pesquisadores quanto os responsáveis não consultaram a criança e/ou adolescente sobre o tratamento proposto. As decisôes de saúde na infância e adolescência dependem dos adultos; contudo, esse grupo foi considerado competente e capaz de decidir situaçóes rotineiras em família. Por outro lado, as crianças e/ou adolescentes sabiam de suas condiçóes de saúde e identificaram a possibilidade da pesquisa/tratamento não lhes trazer benefícios, haja vista a convivência com a realidade da morte de outras crianças, na enfermaria, que sofreram o mesmo tratamento.

Palavras-chave: Criança; Adolescente; Autonomia Pessoal; Consentimento Esclarecido; Epidemiologia Experimental; Técnicas de Apoio para a Decisão

Instituto Fernandes Figueira/ FIOCRUZ-RJ

${ }^{1}$ Enfermeira, Mestre em Ciências da Saúde, Docente do Programa de Pós-Graduaçáo do Instituto Nacional de Câncer. Elaboração do Projeto de dissertaçấo de Mestrado, coleta dos dados, análise dos resultados e elaboração do artigo final.

${ }^{2}$ Médica, Doutora em Ciências pela Fundaçáo Oswaldo Cruz, Pesquisadora e Docente da Pós-graduação no Instituto Fernandes Figueira e na Escola Nacional de Saúde Pública/FIOCRUZ-RJ. Orientação da dissertação, colaboração na análise dos resultados e revisão do artigo final.

Endereço para correspondência: Avenida Adolpho de Vasconcelos, 145/1112 - Barra da Tijuca. Rio de Janeiro (RJ), Brasil. CEP: $22793-380$.

E-mail: vluteixeira@gmail.com 


\section{INTRODUÇÃO}

O processo de trabalho dos pesquisadores/profissionais de saúde remete ao enfrentamento de situaçóes cotidianas, nas quais o conflito moral é constante. A consciência ética é construída pelo ser humano através de seus valores sociais. Nessa perspectiva, os pesquisadores e/ou profissionais necessitam de reflexôes sobre sua prática social, bem como do seu papel na construção da cidadania da criança e/ou adolescente. Assim, o presente estudo procurou aprofundar determinadas questôes referentes a essa problemática.

As discussóes sobre ética em pesquisa nos países em desenvolvimento estão cada vez mais presentes e uma das mais importantes refere-se à vulnerabilidade dos sujeitos da investigação e à possibilidade de serem explorados.

A vulnerabilidade e a proteção da criança e/ou adolescente possuem amplitude e pluralidade de visôes apresentadas por diversos autores e organizaçóes internacionais. A World Health Organization/Council for International Organizations of Medical Sciences (WHO/ CIOMS) promulga uma diretriz que define: "Pessoas vulneráveis são pessoas relativa ou absolutamente incapazes de proteger seus próprios interesses". São atributos necessários para a defesa dos interesses recursos mínimos, como: moradia, alimentação, educação, trabalho e condiçóes de acesso ao sistema de saúde do País. "Assim sendo, a principal característica da vulnerabilidade que essa diretriz identifica é uma capacidade ou liberdade limitadas para consentir na pesquisa ou recusar-se a participar dela"1,2.

As crianças e/ou adolescentes são considerados vulneráveis e, se acrescer a isso o fato de viverem em países em desenvolvimento, aumentam suas vulnerabilidades, em função de condiçốes socioeconômicas desfavoráveis, necessitando, desse modo, de proteção, pois estão mais sujeitas à exploraçáo por parte dos pesquisadores e mesmo dos pais. A falta de acesso ao tratamento de saúde e aos medicamentos leva, muitas vezes, os pais a submeterem seus filhos a pesquisas que náo irão beneficiá-los diretamente ${ }^{3}$.

Por outro lado, em nome da beneficência, os médicos propóem pesquisas, em casos que já não respondem a nenhum tratamento. É preciso discernir a beneficência do paternalismo. Vários autores afirmam que o paternalismo é a ação de contrariar as preferências ou ações conhecidas de outra pessoa, com a justificava de evitar que ela sofra danos. Essa definição é normativamente neutra e, portanto, não presume que o paternalismo seja justificado ou injustificado. Embora a definiçáo assuma um ato de beneficência análogo à beneficência parental, ela não determina se essa beneficência é justificada, inoportuna, obrigatória etc., o que implica numa abordagem insuficiente do paternalismo, pois uma ação paternalista necessariamente determina um limite à escolha autônoma ${ }^{4,5,6,7}$. No caso da populaçáo estudada, verifica-se um paternalismo não normativamente neutro. É um paternalismo revestido de beneficência e que impede o exercício da autonomia.

Preocupados com essa problemática, O National Institute of Health ${ }^{8}$ dos Estados Unidos da América definiu, entre outras coisas, a política de inclusão de crianças e/ou adolescentes em pesquisas, tendo como meta o aumento da participação desses grupos em pesquisas com base no desenvolvimento de novos dados para o tratamento das doenças infantis.

No Brasil, apesar de transcorridos 13 anos desde a aprovação das Diretrizes e Normas Regulamentadoras de Pesquisas em Seres Humanos ${ }^{9}$, através da Resolução do Conselho Nacional de Saúde/MS de número 196, de 10/10/1996, pouco se caminhou no processo de adequação das normas para atender às dificuldades encontradas na obtençáo do consentimento dos sujeitos da investigação, notadamente, da criança e/ou adolescente, levada a efeito pelos pesquisadores da área pediátrica. Deve-se considerar a "vulnerabilidade biopsicossocial de crianças e adolescentes" e, assim, "a pesquisa desenvolvida com estes sujeitos envolve questóes éticas próprias que devem ser respeitadas" 10 .

É certo que a definição da capacidade jurídica fica subordinada à maioridade e que, portanto, é necessário o consentimento dos pais. Contudo nem sempre é suficiente e, por vezes, a criança e/ou adolescente sequer sáo informados da sua participação em pesquisa experimental, sendo considerados incompetentes para tal decisão.

Neste sentido, este estudo teve como objetivo geral analisar o respeito à autonomia de crianças e/ou adolescentes sob tratamento oncológico experimental, aqui visto através do processo de obtenção do Termo de Consentimento Livre e Esclarecido (TCLE) em seus diversos aspectos bioéticos, legais, de desenvolvimento moral e cognitivo deste grupo, no interior do exercício prático da atenção à saúde no que se refere à pesquisa clínica.

Os objetivos específicos da pesquisa foram identificar os esclarecimentos e informaçóes que a criança e/ou adolescente receberam em relação à sua participação na pesquisa; como os pais nortearam a decisão para consentir a participação da criança e/ou adolescente; e os referenciais éticos e estratégias utilizadas pelos pesquisadores na obtenção do consentimento dos pais e crianças e/ou adolescentes.

\section{METODOLOGIA}

Utilizou-se um estudo de caso, de caráter exploratório, de cunho qualitativo. A pesquisa qualitativa, segundo 
Minayo, objetiva responder a questôes muito específicas e tem como preocupação uma realidade que não pode ser quantificada ${ }^{11}$. Um estudo de caso envolve uma análise intensa de um número pequeno de situaçóes e tem, neste caso, um caráter exploratório, já que a proposta foi explorar o tema, objeto do estudo, de forma empírica visando a abrir caminhos para novas investigaçóes.

O estudo foi realizado na Seção de Oncologia Pediátrica do Hospital do Câncer I (HC I), do Instituto Nacional de Câncer (INCA), localizado na cidade do Rio de Janeiro. O local foi escolhido por ser um Centro de Excelência em doenças oncológicas e por desenvolver pesquisas clínicas com novos medicamentos, inclusive em crianças e/ou adolescentes. A investigaçáo escolhida foi submetida ao Comitê de Ética em Pesquisa (CEP) da Escola Nacional de Saúde Pública e aprovada. A análise do material pesquisado fez parte da dissertação de mestrado da autora principal. Esse projeto de pesquisa também foi submetido ao CEP do INCA e aprovado.

Os critérios de inclusão foram: recrutamento da criança e/ ou adolescente para participar em pesquisa clínica envolvendo medicamentos antineoplásicos; habilidades de leitura necessárias para a compreensão do Termo de Consentimento; autorização dos pais ou responsáveis para as crianças e/ou adolescentes participarem da presente pesquisa.

A populaçáo estudada constou de três crianças com idades entre 7 e 8 anos, um adolescente de 14 anos, quatro mães, três pesquisadores responsáveis pela obtenção do Termo de Consentimento e um interlocutor, sempre o mesmo, da Equipe de Saúde da Oncologia Pediátrica, que teve a função de dirimir dúvidas das crianças e/ou adolescentes e de suas mães, perfazendo assim 12 entrevistas. Apesar de o número de crianças ter sido pequeno, trabalhou-se com toda a populaçáo, tendo em vista que todos os entrevistados, no período escolhido, participaram da pesquisa de campo.

Os temas das entrevistas foram formulados a partir de elementos que compóem o processo de obtenção do Termo de Consentimento, de acordo com Beauchamp $\&$ Childress ${ }^{4}$. Esses elementos constituíram as categorias teóricas. $\mathrm{O}$ instrumento de pesquisa foi elaborado a partir da definição das categorias teóricas referentes às leituras relacionadas com o tema central do estudo, isto é, foram escolhidos os elementos que compóem o processo de obtenção do Termo de Consentimento, que pressupóe a autonomia, e depois relacionados às categorias empíricas formuladas a partir da análise das respostas que visaram à percepção dos pais, pesquisadores e sujeitos da pesquisa, em relaçáo à autonomia na infância e adolescência expressa em consentimento para a pesquisa, que foram as seguintes: desrespeito à autonomia; vivendo riscos pela esperança de benefício; decidindo pelas crianças e/ou adolescentes; ambiguidade em relação à autonomia da criança e do adolescente.

Quadro 1. Categorias teóricas

Temática 1: pré-condições para a obtenção do
consentimento
Capacidade para entender e decidir
Voluntariedade no processo de tomada de decisão

Temática 2: elementos da informação

Os riscos e os benefícios

Compreensão dos riscos, dos benefícios e das alternativas

Alternativas mais adequadas

Temática 3: elementos do consentimento

A decisão em favor de uma opção

A autorização para a realização

Temática 4: visão sobre a infância e a adolescência

Essa temática aborda a visão da infância/ adolescência. Foi acrescentada com a finalidade de se apurar a ambiguidade em relação a esses grupos, ora vistos como tendo capacidade para desempenhar determinadas atividades, ora como incapazes

A análise das falas dos entrevistados foi estruturada a partir da transcrição dos depoimentos, baseada na análise indiciária proposta por Villar e Cardoso ${ }^{12}$ que consiste na descoberta de categorias empíricas nas narrativas dos entrevistados. Essas categorias empíricas foram cruzadas com as categorias teóricas escolhidas; e, também, dentro de cada uma delas, foram entrecruzadas as falas dos pesquisadores, das máes e dos sujeitos da pesquisa clínica.

\section{RESULTADOS E DISCUSSÃO}

\section{DESRESPEITO À AUTONOMIA}

O primeiro elemento do processo de consentimento foram as pré-condiçóes para a obtenção do consentimento, isto é, a capacidade para entender e decidir e a voluntariedade no processo de tomada de decisão. As respostas a esse tema estão sintetizadas na falas a seguir:

[...] a criança não tem muita participação ativa no desenvolvimento da conversa. $\mathrm{Na}$ prática fica mais restrita ao pai e a mãe. Geralmente as crianças não são suficientemente grandes para que a gente possa fazê-las muitas vezes entender, em toda sua extensão, todas essas questôes do tratamento (Pesquisador Pássaro Furriel).

[...] no dia ela (adolescente) não ficou sabendo não. $\mathrm{Eu}$ (mãe) não falei nada não. Eu só disse para ela que 
ela, ia fazer uma nova quimioterapia, ela (adolescente) aceitou bem [...] (Mãe Pássaro Caboclinho).

Percebe-se que as crianças foram praticamente ignoradas por não serem consideradas capazes de entender. Tem-se a impressão de que elas ficam invisíveis, porque nem mesmo foi feito o assentimento, denominado pelo (WHO/CIOMS) como "aceitação informada", que requer a participação gradual da criança na tomada de decisão. Entretanto pode-se argumentar que não se justifica moralmente o médico/pesquisador ou mesmo os responsáveis, a priori, não esclarecerem à criança e/ ou adolescente sobre a pesquisa à qual ela estará sendo submetida. Parece-nos, por outro lado, que existe um desconhecimento por parte dos pesquisadores/mães sobre a discussão em relação à capacidade da criança entender e poder optar. A visão paternalista parece prevalecer, julgando tanto os pesquisadores quanto as mães, o que é melhor para a criança, já que ela náo seria capaz de julgar o que seria melhor para ela. Não é levada em conta a idade, o amadurecimento, a capacidade de compreender o que está sendo dito ${ }^{6,13,14}$.

Neste sentido, a autonomia da criança e/ou adolescente não é levada em consideração, o que se traduz pela percepção de que eles não são capazes de entender e, portanto, de decidir o que se coloca como problema, isso inclui também a questão da voluntariedade do sujeito da pesquisa.

Os pesquisadores também questionaram o discernimento de determinadas mães. No entanto isto não foi motivo de impedimento para que elas fossem consideradas sem autonomia para autorizar a participação do filho(a) na pesquisa. A assinatura no Termo de Consentimento parece que é só para constar, não importando o verdadeiro exercício da autonomia.

A gente lida com uma população que normalmente tem dificuldade de entender o nosso linguajar, mesmo que coloquial [...] (Pesquisador Pássaro Furriel).

Entretanto, pela fala ilustrativa, abaixo, verifica-se que os responsáveis sabem muito bem os riscos que as crianças correm, o que significa que compreendem, ao contrário do que os pesquisadores pensam:

[...] o remédio era muito forte [...] era muito sério [...] poderia dar várias reaçóes [...] ou poderia mexer com o coração [...] sabe, infarte, assim, várias coisas (Mãe Pássaro Caboclinho).

Deste modo, cruzando a categoria teórica que prevê as pré-condições para a obtenção do consentimento, ou seja, a análise da autonomia dos que vão consentir e a voluntariedade, na prática, tais elementos não são sequer levados em conta. O pressuposto dos pesquisadores é de que as crianças não são autônomas e, assim, o consentimento deve ser dos responsáveis, mesmo que eles julguem que os mesmos não entendam. Parecem seguir apenas um protocolo e não um processo. É preciso haver um relacionamento mais interativo entre pesquisador e a criança, impedindo as ações que violem sua autonomia e seus direitos ${ }^{15,16}$.

\section{VIVENDO RISCOS PELA ESPERANÇA DE BENEFícIO}

O segundo elemento do processo de consentimento enfoca os componentes da informação, isto é, os riscos e os benefícios; compreensão dos riscos, dos benefícios e das alternativas e a alternativa mais adequada.

Observa-se, em primeiro lugar, conforme se pode depreender das falas abaixo, que não se emprega a palavra pesquisa, quando é comunicado à criança e/ou adolescente seu ingresso num protocolo, o que pode ser interpretado como as crianças não terem sido suficientemente informadas e esclarecidas sobre a real situação proposta. Os sujeitos das pesquisas incorporaram os discursos das mães e pesquisadores de que seu ingresso na pesquisa deve-se a um tratamento que vai curá-las, melhorar a sua saúde ou algo que vai aliviar seus sintomas, ou seja, curá-la.

Verificou-se, também, certa ambiguidade em relação à palavra pesquisa quando ela é utilizada pelo pesquisador em determinado momento. $\mathrm{Na}$ realidade, ele se refere ao tratamento da doença. Os pais também entendem a pesquisa como esperança de cura ou controle da doença.

[...] eu até procuro explicar a criança que eu vou fazer algum tipo de tratamento, o que é, para que é. Mesmo que aquilo pareça que é um... Levando a um sofrimento, eu gosto de explicar que tem uma finalidade de cura [...] (Pesquisador Pássaro Estrelinha).

[...] eu sabia que a situação dele era grave, então, a única coisa que a gente tinha que fazer era tentar alguma medicação que pudesse controlar a doença (Mãe Pássaro Tico-Tico).

[...] eu sei que é tratamento (Adolescente Pássaro Grimpeiro).

Vai ser boa porque vai melhorar. Abaixou o dodói e não dói mais (Criança Pássaro Barulhento).

Os riscos são explicados às mães, porque elas verbalizaram sobre eles nos depoimentos. Entretanto nota-se que os riscos são minimizados pela esperança do benefício, que seria a cura ou a sobrevida.

[...] é uma esperança nova para a família no sentido de poder dar mais uma forma de tratamento, que 
é sempre o que eles querem. É que eles sempre têm aquela ideia de que essa medicação vai curar ou vai pelo menos resolver a situaçáo da criança (Pesquisador Pássaro Enferrujadinho).

O resultado ressalta a magnitude do problema dos pesquisadores para explicar diretamente à criança e/ou adolescente os riscos da pesquisa. Estes enfrentam um conflito: por um lado necessitam dar informação acurada sobre a pesquisa, por outro, não têm autorização dos pais para falar sobre esses riscos com a criança, acabando por vigorar a regra do privilégio terapêutico, o que não poderia ocorrer em face de uma pesquisa com graves riscos ${ }^{3}$. Este aspecto, no entanto, pode ser interpretado de outro modo: os pesquisadores acreditam na incapacidade das crianças e/ou adolescentes em entender/suportar a verdade de que elas são pacientes fora de possibilidades terapêuticas, que seu ingresso num protocolo experimental porta riscos máximos e as chances de benefício são muito poucas $^{17,18,19}$.

Os pais consideram a criança incapaz de entender a sua condição de saúde, mesmo convivendo com a realidade de experiências de outras crianças no hospital. As mães demonstraram preocupação em esconder dos filhos os riscos de insucesso da pesquisa/tratamento, pois teriam que falar de forma explícita sobre a alternativa de cuidados paliativos, no caso das crianças, inexistentes para amenizar o processo de morrer ${ }^{20,21}$. O fato é que nem sequer se cogita dar como alternativas os cuidados paliativos para crianças. Só resta tentar tratamentos que acabam por fazer sofrer e não levam à cura, e sim à morte em sofrimento ${ }^{22}$.

\section{DECIDINDO PELAS CRIANÇAS E/OU ADOLESCENTES}

No terceiro elemento do processo, isto é, nos componentes do consentimento, constata-se que não houve opçáo, sendo a decisão tomada pelos responsáveis por verem no novo medicamento uma esperança de cura ou sobrevida para o filho. A autorização, assim como a assinatura do Termo de Consentimento em sua maioria, foi feita pelas mães. As crianças e/ou adolescentes não foram consultados e nem assinaram o Termo de Consentimento, como falado pela adolescente: "Não [...] não assinei” (Criança Pássaro Amarelinho).

Para os pesquisadores, não há uma reflexão de que se possa estar fazendo uma obstinação terapêutica ou mesmo acelerando a morte, tendo em vista a ocorrência de óbitos frequentes com muito sofrimento em crianças submetidas a novos protocolos com medicamentos experimentais.

[...] A decisão foi baseada na melhora dela (adolescente), porque ela já tinha feito de tudo aqui no hospital e não teve jeito (Mãe Pássaro Caboclinho).
Pode-se observar que o conteúdo das informaçóes sobre a pesquisa, riscos e benefícios, enfatizando o possível benefício, são estratégias utilizadas pelos pesquisadores para influenciar a tomada de decisão dos pais e destes aos filhos. Exalta-se o prejuízo da não entrada na pesquisa; há dificuldade, por parte dos pesquisadores, em aceitar a recusa, seja do sujeito da investigação, seja dos responsáveis, como também se enfatiza a esperança de cura ou melhora.

Essas inferências demonstram que a decisão, em favor de uma opção, e a autorizaçáo para a realização da pesquisa estão submetidas à vontade dos responsáveis, negando-se à criança e ao adolescente a oportunidade de escolha, já que é sobre seu corpo que experiências serão realizadas.

\section{AMBIGUIDADE EM RELAÇÃO À AUTONOMIA DA CRIANÇA E/OU DO ADOLESCENTE}

Em relaçáo à última temática, pode-se observar que a visão que se tem das crianças e adolescentes são determinantes para o que se vê nas temáticas anteriores. Existe uma ambiguidade em relação à autonomia da criança e/ou do adolescente, ora vistos como incapazes de entendimento, ora como pessoas adultas, plenamente capazes de compreender e decidir ${ }^{23}$.

[...] a criança é um reflexo muito grande dos pais. Depende muito da faixa etária. Porque, quanto menor a criança, ela tem menos possibilidade de decidir o que quer, o que é bom para ela. Agora, na medida em que ela vai ficando maior, o que a gente vê é que ela consegue se defender de coisas do tipo assim... É normal a gente chegar para a criança e falar que tem que lavar as mãos antes de examinar (Pesquisador Pássaro Enferrujadinho).

Analisando a fala do pesquisador, verifica-se que ele associa a busca da autonomia pelo adolescente como criação de problemas:

[...] já o adolescente é uma situação diferente porque o adolescente é o inverso. Porque ele quer, ele está naquela questão da afirmação da [...] autonomia dele né [...] que ele mais está querendo ter liberdade, então, são pacientes que trazem problemas neste sentido (Pesquisador Pássaro Enferrujadinho).

De acordo com as mães, o mesmo se dá. As crianças participam da vida familiar, emitem opiniôes, desempenham tarefas de adultos, tomam decisóes e têm responsabilidades, mesmo estando gravemente doentes, o que se configura como uma certa autonomia, pelo menos dentro do lar e em seu meio social ${ }^{23,24,25}$. 
[...] eu digo porque a adolescente Pássaro Grimpeiro é tão animada, que ela faz a quimioterapia, chega em casa ela é táo assim [...] esperta para fazer [...] ir para a cozinha, fazer bolo, ela limpa a casa, ela é muito organizada. Ela briga até com os irmãos (Mãe Pássaro Caboclinho).

Verifica-se, pelas falas, que os adultos apresentam uma percepção ambígua da criança e/ou adolescente, sendo considerados adultos para determinadas situaçóes e crianças para outras.

Quanto às crianças e aos adolescentes, eles acabam por permitir que os pais decidam por eles, acreditando que o desejo dos pais é para o seu bem-estar, o que denota uma posição de heteronomia, explicável até certa idade do seu desenvolvimento moral. Essa contradição entre o exposto na teoria e a prática revela o que se passa no imaginário social, isto é, a ambiguidade em relação à sua condição, acabando por influenciar os próprios adolescentes e crianças em condiçôes de exercer sua autonomia de escolha ${ }^{23,24,25}$. Como a autonomia é negada em determinadas circunstâncias, como no caso de decisóes médicas, não há como crianças e adolescentes se posicionarem contra. Eles são invisíveis no processo, como se pôde demonstrar, e isto faz com que hajam de forma heterônoma. A autonomia deve ser promovida e este é um papel que cabe tanto aos pais como aos profissionais de saúde. $\mathrm{Na}$ realidade, o que foi visto foi o contrário. Toda tentativa de expressar a autonomia foi ignorada, como foi visto nas entrevistas com as crianças e adolescentes.

\section{CONCLUSÃO}

A autonomia, traduzida neste trabalho como o exercício do consentimento livre e esclarecido, foi discutida à luz da bioética. Para tal, foram verificados o referencial ético que deve guiar os profissionais e as estratégias utilizadas pelos pesquisadores na obtenção do consentimento. Também foram analisadas as percepçóes dos pais e das crianças e adolescentes em relação às informaçóes recebidas para a tomada de decisão em participar da pesquisa.

Verificou-se também que, para que o consentimento tenha valor, há necessidade de se estabelecer critérios para a capacidade de consentir. Essa capacidade de decisão autônoma situou-se entre dois conceitos que divergiram entre si: o desenvolvimento cognitivo que pode ser maior em determinadas crianças, como as que apresentam longa enfermidade, e o critério legal de maioridade civil que advoga a incapacidade para menores de 18 anos. Constatou-se que a ideia prevalente ainda é a do critério legal, seja por medo ou por desinformação. Analisou-se, de outro modo, a discussão em relação à problemática da autonomia em crianças e adolescentes, na qual se pode concluir que todos os autores pesquisados preconizam que a criança seja considerada em parâmetros mais flexíveis do que simplesmente pela idade cronológica. $\mathrm{O}$ fato de não ter assegurado juridicamente a capacidade de decidir não quer dizer que os menores de idade não tenham nenhuma autonomia. A criança deve ser vista individualmente, informada e esclarecida de acordo com seu entendimento, procurando-se buscar seu consentimento ou assentimento. Náo é possível o sujeito da pesquisa, pelo fato de ser criança ou adolescente, ficar invisível na hora da tomada de decisão.

Adquiriu também importância, neste trabalho, a percepção sociocultural da infância que os pais e pesquisadores e as próprias crianças e adolescentes revelaram. Este trabalho subsidiou a análise das crenças e valores morais adotados por eles no respeito ou não da decisão autônoma da criança e do adolescente, mostrandonos a ambiguidade de que se revestem seus olhares.

Também, face aos resultados encontrados no campo, chegou-se a algumas outras conclusóes: 1) analisando o princípio da autonomia a partir do processo de consentimento livre e esclarecido, observou-se que a autonomia da criança e do adolescente é desconsiderada. Os pesquisadores e as mães justificam essa conduta paternalista pela crença de que as crianças e adolescentes não são capazes de entender e decidir o que é melhor para eles. Desta forma, não há voluntariedade do sujeito em participar da pesquisa; 2) no que concerne ao segundo elemento do processo, concluiu-se que há uma imprecisão entre os termos pesquisa e tratamento ocasionando uma conotação errada da análise dos riscos e benefícios. Prevalece a utilização pelos pesquisadores do termo tratamento em substituição ao termo pesquisa. As mães, as crianças e os adolescentes também acreditam ser a pesquisa um novo tratamento que será capaz de curar ou melhorar os sintomas. Neste contexto, permitem a participação dos filhos ignorando os riscos máximos, pois a alternativa seria a morte certa. Aqui, se trata da esperança correndo riscos, pois, se essas crianças já não respondem aos tratamentos convencionais, isto significa a terminalidade da vida. Ao oferecer uma nova droga, há esperanças, mesmo que remotas ou inexistentes, de aumentar a sobrevida ou mesmo curar. Quando se fala em alternativas, pressupóe-se a existência de, pelo menos, duas opçóes a serem oferecidas. Em outros termos, os pesquisadores deveriam propor a opção cuidados paliativos versus nova droga experimental, e não simplesmente ofertar a pesquisa como a única opção existente. Os novos medicamentos comportam riscos muito graves, podem aumentar o sofrimento revestindo-se de, não raras vezes, uma autêntica distanásia, isto é, um prolongamento da vida por dias, semanas ou meses; 3) no terceiro elemento do processo 
que se refere à decisão e à autorização, concluiu-se que não há participação da criança e/ou adolescente. Quando ocorre recusa da criança em participar de novo protocolo de pesquisa, tanto os pesquisadores como as mães verbalizam que deve prevalecer a conduta paternalista. $\mathrm{O}$ argumento utilizado para justificar esta posiçâo se prende à esperança de cura ou melhora. Preconiza-se o assentimento em lugar do consentimento quando se abordam esses grupos. $\mathrm{O}$ assentimento pressupóe que se deve ajudar a criança e o adolescente, de maneira apropriada a seu grau de desenvolvimento, para que entenda a natureza de sua condição; que seja informada sobre o que deve esperar da pesquisa; de uma avaliação do grau de sua situação sem estar influenciada por pressóes; da expressáo de voluntariedade da criança na aceitação do cuidado proposto; e, nas situaçóes graves, como foram os casos aqui relatados, em que o tratamento proposto se impôs, e que, independente da aceitação da criança, ela deveria ser esclarecida e informada e jamais ser enganada; 4) as percepçôes da infância/adolescência pela sociedade mostram também a ambiguidade presente nos adultos: ao mesmo tempo aparece a imagem da criança como um ser biológico e socialmente vulnerável que paradoxalmente se contrapóe à imagem emergente da criança de direitos, igualitária no sentido de ter acesso a todas as informaçóes do mundo dos adultos. Verificou-se que a infância e adolescência dependem dos adultos para as decisôes de saúde. Entretanto, quando se encontram fora do contexto da doença, são considerados competentes e plenamente capazes de compreender e decidir situaçóes do dia a dia em família.

Concluiu-se que o processo de consentimento não ocorre porque a criança e o adolescente mostram-se invisíveis na tomada do consentimento. Eles são falados pelos outros que os consideram incapazes de compreender os procedimentos da pesquisa. Entretanto essa mesma criança fala da sua doença, identifica a possibilidade da pesquisa/tratamento náo ter benefícios, porque convive com a realidade de outras crianças que morrem; e é sobre sua vida, seu corpo que outros decidem por ela sem o seu consentimento esclarecido. A visão do adolescente é considerada problemática porque ele quer decidir de acordo com sua vontade própria, surgindo conflitos entre a família e a equipe de saúde.

Acredita-se na importância de se preservar o exercício da autonomia, em qualquer idade, como respeito à dignidade da pessoa, conforme proposto pelos documentos e declaraçóes em relação à pesquisa com seres humanos, especialmente quando o sujeito da investigação é criança ou adolescente.

Espera-se ter contribuído para reflexáo dos pesquisadores, dos membros de Comitês de Ética em Pesquisa, que cotidianamente julgam e avaliam aspectos éticos da pesquisa, que envolvem decisôes, conflitos de interesses, confrontos jurídicos, valores morais e sociais. Cabe a esses membros poder contribuir para o respeito à autonomia da criança e do adolescente melhorando as pesquisas em curso no país.

\section{Declaraçáo de Conflito de Interesses: Nada a Declarar}

\section{REFERÊNCIAS}

1. Macklin R. Bioética, vulnerabilidade e proteção. In: Garrafa V, Pessine I. organizadores. Bioética: poder e injustiça. São Paulo: Loyola; 2003. p. 59-70.

2. Neves MCP. Bioética, vulnerabilidade e proteção. In: Garrafa V, Pessini L, organizadores. Bioética: poder e injustiça. São Paulo: Loyola; 2003. p. 487-98.

3. Mota CAJ. A criança como sujeito de experimentação científica: uma análise histórica dos aspectos éticos. [tese]. Belo Horizonte: Universidade Federal de Minas Gerais, Faculdade de Medicina; 1998.

4. Beauchamp TL, Childress JF. Princípios de ética biomédica. São Paulo: Loyola; 2002.

5. Muñoz RD, Fortes PAC. O princípio da autonomia e o consentimento livre e esclarecido. In: Costa SIF, Garrafa V, Oselka G, organizadores. Iniciação a Bioética. Brasília: Conselho Federal de Medicina; 1998. p. 53-70.

6. American Academy of Pediatrics. Committee in Bioethics. Informed consent, parenteral permission and assent in pediatric practice. Pediatrics. 1995; 95 (2):314-7.

7. Almeida JLT. Respeito à autonomia do paciente e consentimento livre e esclarecido: uma abordagem principialista da relação médico-paciente. [tese]. Rio de Janeiro: Escola Nacional de Saúde Pública; 1999.

8. National Institute of Health. Office of Human Subjects Research. [homepage na internet]. Bethesda, MD. Office of Human Subjects Research. The Belmont Report. Ethical principles and guidelines for the protection of human subjects of research. 1979. [cited $2004 \mathrm{dec}$ 13]. Available from: http://ohsr.od.nih.gov/guidelines/ belmont.html\#gob.

9. Conselho Nacional de Saúde. Comissão Nacional de Ética em Pesquisa. Normas para pesquisa envolvendo seres humanos. (Res. CNS. No 196/96 e outras). 2a ed. amp. 1a reimp. [monografia na internet]. Brasília: CNS; 2003. Disponível em: http://dtr2001.saude.gov. br/editora/produtos/livros/pdf/03_0559_MP.pdf.

10. Gaiva MAM. Pesquisa envolvendo crianças: aspectos éticos. Bioética 2009;17(1): 135-46.

11. Minayo MCS. O desafio do conhecimento: pesquisa qualitativa em saúde. São Paulo. Rio de Janeiro: Hucitec /Abrasco; 1996.

12. Villar MAM, Cardoso MHCA. Residência médica em pediatria: no campo de prática. Cad 
Saúde Pública. $2002 \mathrm{Fev}$ [acesso em 2003 Mar 07];18(1):329-39. Disponível em: http://www. scielo.br/scielo.php?script=sci_arttext\&pid=S0102$11 X 2002000100034 \& \operatorname{lng}=$ pt\&nrm=iso.doi: $10.1590 /$ S0102311X2002000100034

13. Clotet J, Goldim JR, Francisconi CF. Consentimento informado e sua prática na assistência e pesquisa no Brasil. Porto Alegre: EDIPUCRS; 2000.

14. Conselho de Organizaçôes Internacionais de Ciências Médicas. Diretrizes éticas internacionais para a pesquisa biomédica em seres humanos. São Paulo: Edições Loyola; 2004.

15. Harrison C, Kenny NP, Sidarous M, Rowell M. Bioethics for clinicians: 9. involving children in medical decisions. CMAJ [serial on the Internet]. [cited 1997 Mar 15];156(6):825-8. Available from: http://www. pubmedcentral.nih.gov/articlerender.fcgi?tool=pubme d\&pubmedid $=9084389$

16. Massimo LM, Wiley TJ, Casari EF. From informed consent to shared consent: a developing process in pediatric oncology. Lancet Oncology [serial on the Internet]. \{cited 2004 jun 15] ; 5(6):384-7. Available from: http://www.ncbi.nlm.nih.gov/pubmed/1517236 0 ?ordinalpos $=1$ \&itool=EntrezSystem 2. PEntrez .Pubmed. Pubmed_ResultsPanel.Pubmed_DiscoveryPanel. Pubmed_RVAbstractPlus

17. Frota MGC. A cidadania da infância e adolescência. In: Carvalho A, Salles F, Guimarães M, Ude W, organizadores. Políticas públicas. Belo Horizonte: Editora UFMG; 2002. p. 59-85.
18. Sterling CM, Friedman AG. Empathic responding in children with a chronic illness. Child Health Care. 1996;25(1):53-9.

19. Sharav VH. Children in clinical research: a conflit of moral values. Am J Bioeth [serial on the Internet]. 2003 winters;3(1):12-59. Available from: http://www.ncbi. nlm.nih.gov/pubmed/16192118?ordinalpos=2\&itool= EntrezSystem2.PEntrez.Pubmed.Pubmed_ResultsPanel. Pubmed_RVDocSum

20. Ribeiro IB. O significado do câncer na adolescência: uma análise compreensiva por portadores de neoplasia. [dissertação]. Rio de Janeiro: Faculdade de Enfermagem. Universidade do Estado do Rio de Janeiro; 2002.

21. Castiel LD. Aspectos epistemológicos, teóricos e disciplinares. [monografia na Internet]. Rio de Janeiro: Fiocruz; 1996. [acesso em 2004 jul 20]. Disponível em: http://www.ensp. fiocruz.br/projetos/esterisco/aspectos.htm.

22. Silva CHD. Quando o tratamento oncológico pode ser fútil? Do ponto de vista do saber-fazer médico. Revista brasileira de cancerologia. 2008;54 (4):401-10.

23. Castro LR. Da invisibilidade à ação: crianças e jovens na construção da cultura. In: Castro LR, organizadora. Crianças e jovens na construção da cultura. Rio de Janeiro: Nau editora; 2001. p. 19-46.

24. Braz M, Castro C, Miranda BABBA. As crianças sem família, a violência e a parentalidade. Rio de Janeiro; 2009. No prelo

25. Postman N. O desaparecimento da infância. Rio de Janeiro: Graphia Editorial; 1999. 


\section{Abstract}

This study aimed to analyze the respect for the principle of autonomy concerning children and/or adolescents under experimental oncology treatment by obtaining Informed Consent, for research purposes, through an exploratory and qualitative study case. The data were obtained through thematic interviews and interpreted by clue analyses. Three children, an adolescent, four researchers and four mothers were interviewed. The results showed that children and/or adolescents' autonomy, even if relative, is not taken into consideration, which may be understood when the informed consent is not signed, since parents and researchers believe these children and/or adolescents are not able to understand the risks and benefits of the research. From this perspective, the parents' decision to allow the children and/or adolescents to participate in this experimental treatment was based on the hope of their children's cure and that is why they signed the informed consent. Neither researchers nor parents talked to the children and/or adolescents about the treatment proposed. Decisions on health during childhood and adolescence periods depend on adults; however, this group was considered competent and able to decide on routine situations in family. On the other hand, the children and/or adolescents were aware of their health conditions and of the research/treatment's possible lack of benefits, considering they have witnessed the deaths of other children, who underwent the same treatment in the ward.

Key words: Child; Adolescent; Personal Autonomy; Informed Consent; Epidemiology, Experimental; Decision Support Techniques

\section{Resumen}

El presente estudio propone un análisis del respeto al principio de la autonomía en niños y/o adolescentes, bajo tratamiento oncológico experimental, mediante el proceso de obtención del Término de Consentimiento Libre y Esclarecido (TCLE), para fines de investigación, a través de un estudio de casos, de carácter exploratorio, de cuño cualitativo. Los datos fueron recolectados a través de entrevistas temáticas e interpretados por el análisis indiciario. Fueron entrevistados: tres niños, un adolescente, cuatro investigadores y cuatro madres. Los resultados mostraron que la autonomía, incluso relativa, del nińo y/o adolescente no se tiene en cuenta, lo que se traduce en la no obtención del TCLE, puesto que los padres e investigadores creen que estos niños y/o adolescentes no son capaces de comprender los riesgos y beneficios de la investigación. En este sentido, la decisión de los padres para permitir la participación del niño y/o adolescente en ese tratamiento experimental se basa en la esperanza de curación para su hijo y, por lo tanto, son ellos quienes firman el TCLE. Tanto los investigadores como los responsables no consultaron al niño y/o adolescente sobre el tratamiento propuesto. Las decisiones de la salud en la infancia y adolescencia dependen de los adultos; sin embargo, ese grupo fue considerado competente y capaz de decidir situaciones rutineras en familia. Por otro lado, los niños y/o adolescentes sabían de sus condiciones de salud e identificaron la posibilidad de la investigación/tratamiento no traerles beneficios, teniendo en cuenta la convivencia con la realidad de la muerte de otros niños, en la enfermería, que sufrieron el mismo tratamiento.

Palabras clave: Niño; Adolescente; Autonomía Personal; Consentimiento Informado; Epidemiología Experimental; Técnicas de Apoyo para la Decisión 